\title{
Smoking by people with mental illness and benefits of smoke-free mental health services $^{\dagger}$
}

\author{
Jonathan Campion, Ken Checinski, Jo Nurse \\ \& Ann McNeill
}

Abstract Smoking is the largest single cause of preventable illness in the UK. Those with mental health problems smoke significantly more and are therefore at greater risk. The new Health Act (2006) will require mental health facilities in England to be completely smoke-free by 1st July 2008. This article reviews the current literature regarding how smoking affects both the physical and mental well-being of people with mental health problems. It also considers the effects of smoke-free policy in mental health settings.

This article continues the authors' discussion of their literature search on smoking by people with mental health problems (see pp. 208-216).

The World Health Organization (2006) estimated that 5 million deaths worldwide occurred in 2006 from tobacco consumption. This figure is expected to double by 2020 , with $70 \%$ of the deaths occurring in low- and middle-income countries. In addition, the report estimated that 650 million people, or half of the world's smokers alive today, will die prematurely from a tobacco-related disease if they continue to smoke. Even in the UK, smoking is the largest single cause of preventable illness and premature death: 106000 people died of smoking-related diseases in 2002 (Department of Health, 2006), with an additional 10000 deaths each year due to passive smoking (Jamrozik, 2005). In the UK in 2006, 22\% of adults were smokers and two-thirds of them wanted to give up (Goddard, 2008). Of those who smoke regularly, one in two die 15 years prematurely and one in four dies 23 years prematurely (Doll et al, 2004).

Smoking is significantly associated with increased prevalence of all major psychiatric disorders (Farrell

${ }^{+}$See pp. 198-207 and 208-216, this issue. et al, 2001). Until relatively recently, this area received little attention in the UK, despite political imperatives to reduce health inequalities. Other parts of the UK have varied in their response to the higher levels of smoking among people with mental health problems. In Wales, the Smoke-free Premises Regulations 2007 exempts designated rooms in residential mental health treatment settings but does not exempt psychiatric hospitals. In Scotland, the Smoking, Health and Social Care (Scotland) Act 2005 offers guidance on exempted areas in psychiatric settings. In Northern Ireland, the Smoke-free (Exemptions and Vehicles) Regulations 2007 gave temporary exemption for mental health units which ceased on 30 April 2008. In Ireland, the Public Health (Tobacco) Act 2002 and the Public Health (Tobacco) (Amendment) Act 2004 exempt psychiatric hospitals and nursing homes.

In England, the Health Act 2006 legislation stipulated that all enclosed public areas and workplaces would become smoke-free in a bid to reduce smoking-related morbidity and improve health. Between 1 July 2007 and 30 June 2008, mental health units providing residential accommodation were able to retain designated smoking rooms meeting specific conditions. On 1 July 2008, this Act

Jonathan Campion is a specialist psychiatry registrar on the St George's Psychiatry Training Scheme in London (Springfield Hospital, 61 Glenburnie Road, London SW17 7DJ, UK. Email: jonathan_campion@yahoo.co.uk). Areas of interest and research include public mental health, addiction, transcultural psychiatry and mental health service provision in low-income countries. Ken Checinski is a senior lecturer in addictive behaviour at St George's, University of London, and consultant psychiatrist with the Respond NHS substance misuse service in Surrey. Research and clinical interests include smoking and mental health, dual diagnosis, post-traumatic stress and public health education. Jo Nurse is national lead for public mental health and well-being at the Department of Health, England. She works as a consultant in public health in a regional public health group. Areas of interest and experience include health promotion, sexual health, healthy prison settings, mental well-being, substance misuse, violence and abuse. Ann McNeill is Chair of Health Policy and Promotion in the Department of Epidemiology and Public Health at the University of Nottingham. Her main research and policy interests cover nicotine and tobacco product regulation, smoking and mental health issues, smoking cessation and harm reduction, and the development of dependence on smoking. 
will include any enclosed or substantially enclosed part of any mental health establishment, thereby changing the culture and ethos of mental health services, which have until now paid less attention to physical health. This reflects a wider change in the perception of the importance of well-being with an emphasis on the promotion of physical, mental and social well-being in both the general population and those with mental health problems (Nurse \& Campion, 2006). (For a review of the reasons for inclusion of mental health settings in the Act see Campion et al, 2006).

\section{Effects of smoking on physical health and morbidity}

The cost of smoking-related mortality in the UK during 1997 was estimated to be $£ 80$ billion (Royal College Physicians, 2000) and one in five deaths in the UK could be attributed to smoking. Smoking increases the risks of a wide range of diseases, the major ones being respiratory disease, circulatory disease and several cancers. It also poses a significant risk to maternal and foetal health. Exposure to environmental tobacco smoke increases the risk of lung cancer and ischaemic heart disease by up to $25 \%$ (Scientific Committee on Tobacco and Health, 2004). Heavy passive smoking is associated with a $50-60 \%$ increase in the risk of coronary heart disease (Whincup et al, 2004).

\section{Smoking in people with mental health problems}

\section{Increased levels of smoking}

People with mental health problems are more likely to smoke and to smoke more heavily than the general population. However, smoking is associated not only with the prevalence but also with first-ever incidence of mental disorders (Cuijpers et al, 2007). In a prospective, population-based epidemiological study, people who smoked but had no history of mental disorder had an increased risk of developing such a disorder; this risk remained significant after correcting for major risk indicators of mental disorders (incidence rate ratio $R R=1.56, P<0.05$ ). Smoking tobacco is significantly associated with increased prevalence of all major psychiatric disorders (Farrell et al, 2001) and the probability of any mental health problem in smokers is double that in non-smokers (22.4 v. 12.2\%). In a large population survey of psychiatric morbidity in the UK, $64 \%$ of those with probable psychosis were smokers compared with $29 \%$ without psychosis (Coultard et al, 2000). Smokers with mental health problems smoke more heavily, are more nicotine-dependent and have smoked for longer than smokers in the general population (Kumari \& Postma, 2005). The highest levels of smoking are among patients in psychiatric units, where up to $70 \%$ smoke, $50 \%$ heavily (Jochelson \& Majrowski, 2006); rates are lower for people with mental illnesses living at home. Indeed, psychiatric hospitalisation can also lead non-smokers to become smokers (Lawn et al, 2002). Heavy smoking is associated with increased severity of psychotic illness, poorer outcomes and more frequent hospital admissions (Aguilar et al, 2005).

Although smokers with schizophrenia or depression may recognise the risks of smoking, there is evidence that they find cigarettes more appealing than do the general population (Spring et al, 2003). In 2005, tobacco companies in the USA spent more than $\$ 13$ billion on advertising and promotion (Federal Trade Commission, 2007) and people with mental health problems may be more vulnerable to such influence. A recent study analysed previously secret tobacco industry documents which indicated that the tobacco industry monitored or directly funded research supporting the idea that individuals with schizophrenia were less susceptible to the harms of tobacco and that they needed tobacco as selfmedication (Prochaska et al, 2008). The authors reported that the tobacco industry promoted smoking in psychiatric settings by providing cigarettes, supporting efforts to block hospital smoking bans and engaging in a variety of activities that slowed development of treatment for nicotine dependence treatment for this population. Box 1 summarises other explanations for the higher levels of smoking in people with mental health problems.

\section{Physical health and mortality rates}

Mortality rates for people with schizophrenia show a life expectancy roughly $20 \%$ shorter than that of the general population (Hennekens et al, 2005). More than two-thirds of people with schizophrenia, compared with about a half in the general population, die of coronary heart disease. The main factors for this excess mortality are cigarette smoking, obesity, diabetes and hypertension. Mental illness also predicts higher morbidity from respiratory disease, with a diagnosis of schizophrenia increasing risk of death from respiratory disease to 10 times that for the general population (Joukamaa et al, 2001). Smoking cessation before middle age can avoid more than $90 \%$ of the lung cancer mortality risk attributable to tobacco (Peto et al, 2000). It is likely that high rates of smoking result in this increased risk of many smoking-related diseases and that this is responsible for most of the excess natural mortality of people with mental health problems (Brown et al, 2000). 


\section{Box 1 Possible reasons why people with mental health problems smoke more}

\section{Causative}

Smoking may lead to mental health problems such as anxiety disorders

\section{Relief of stress}

Smokers often report stress relief and enjoyment as reasons for their smoking

\section{Self-medication}

Smoking could be ameliorating the effects of mental health problems

\section{Increased vulnerability to smoking}

People with mental health problems are likely to experience higher levels of distress and therefore find it more difficult to stop behaviour that has immediate effect despite being harmful in the longer term.

\section{Inaccessibility of health messages}

People with mental health problems may be more vulnerable to misleading messages about tobacco

\section{Deprivation}

This is associated with both cigarette smoking and mental health problems

\section{Institutional and cultural factors}

- Higher rates of smoking are found in those in institutions than those living at home, and psychiatric hospitalisation leads some non-smokers to become smokers

- Some staff and patients believe that smoking alleviates both distress and medication sideeffects, and mistake nicotine withdrawal for symptoms of psychiatric illness

- Reinforcement of smoking behaviour occurs when cigarettes are used to reward or punish patients

Relief of boredom and facilitating of social contact

The risk of many diseases, in particular respiratory and cardiovascular disease, in people with mental health problems could therefore be preventable by appropriate support to quit smoking. This would significantly improve physical health, life expectancy and well-being. Moreover, results of a population survey showed that people whose mental illness had remitted were not at increased risk for subsequent smoking, in contrast with individuals with active disorders (Breslau et al, 2004). There are therefore additional and previously unrecognised public health benefits of early treatment of mental disorders.

\section{Smoking and suicide as causes of mortality}

Since one in two regular smokers dies prematurely (Doll et al , 2004), at least 50\% of people with serious mental illness who persist in smoking regularly will die prematurely from smoking-related diseases. This compares with a $10 \%$ lifetime risk of suicide, a cause of death that has received a great deal of attention from government and the psychiatric profession. In addition, there is a link between smoking and suicide, as studies have indicated that smokers are more likely to think about suicide (Wilhelm et al, 2004) and have higher suicide rates (Malone et al, 2003).

\section{Smoking as a psychiatric disorder}

The relationship between mental illness and smoking is complex, particularly if smoking itself is considered as a psychiatric disorder. Nicotine dependence fulfils DSM-IV core criteria for mental disorder, being a 'clinically significant behavioural or psychological syndrome or pattern that occurs in an individual and associated with distress, disability and a significantly increased risk of suffering death and disability' (American Psychiatric Association, 1995). Both nicotine dependence (305.10) and nicotine withdrawal are included as disorders in DSM-IV. Chapter V of ICD-10 includes mental and behavioural disorders due to use of tobacco and defines both dependence (F17.2) and withdrawal (F17.3) (World Health Organization, 1992). Nicotine dependence is therefore the most prevalent mental disorder and typically persists for decades once established, with very low rates of permanent remission: less than $2-3 \%$ a year in the UK (Taylor et al, 2006).

\section{Effects of smoking on neurotransmitters}

Nicotine crosses the blood-brain barrier several seconds after inhalation and binds to nicotinic cholinergic receptors. In the central nervous system this causes the release of neurotransmitters such as noradrenaline, serotonin, dopamine, acetylcholine, $\gamma$-aminobutyric acid and glutamate. Chronic smoking causes up-regulation of nicotinic receptors (Gotti et al, 1997), in contrast to the down-regulation of most neurotransmitter receptors on exposure to agonists.

Smoking inhibits the enzyme monoamine oxidase $\mathrm{B}$ (MAO-B), which is responsible for the catabolism of several brain neurotransmitters, including dopamine, serotonin and noradrenaline (Haustein et al, 2002). Smokers therefore have lower brain MAO-B 
levels than non-smokers, although levels return to normal on quitting (Khalil et al, 2000). Inhibition of MAO-B causes dopamine levels to increase, thereby making smoking potentially rewarding. Long-term smokers have been found to have neurochemical abnormalities in the locus cerulus similar to those seen in animals treated with antidepressant drugs and opposite to those observed in people with major depression (Klimek et al, 2001). Since MAO inhibitors are effective antidepressants, these findings suggest that smoking might have some antidepressant effects (Hughes, 1999). The association between cigarette smoking and the presence and severity of suicidal behaviour across major psychiatric disorders has been postulated to be related to lower brain serotonin function in smokers with depression (Malone et al, 2003).

Nicotine may be particularly reinforcing in schizophrenia because it stimulates the subcortical reward system and the prefrontal cortex, which both appear to be hypofunctional in schizophrenia (Chambers et al, 2001). Watkins et al (2000) suggested that the ability of nicotine to trigger dopamine release in mesolimbic reward centres might make smoking one of the few reinforcers able to overcome the anhedonia that characterises both schizophrenia and depression. In addition, noradrenergic effects of nicotine may account for increased attentiveness and improved performance of repetitive tasks (Sullivan \& Covey, 2002).

\section{Smoking and specific psychiatric disorders}

\section{Smoking and depression}

The national survey of psychiatric morbidity (Coultard et al, 2000) found that people with depressive or anxiety disorders are twice as likely to smoke as those without. A clear relationship was noted between smoking prevalence and number of depressive/anxiety symptoms as measured by the revised version of the Clinical Interview Schedule (CIS-R). General population surveys in both Australia and the USA have also found that smokers have higher rates of depression than nonsmokers (Wilhelm et al, 2003). As previously noted, smokers are more likely to think about suicide and have higher suicide rates.

Evidence suggests that smoking increases risk of depression (Klungsoyr et al, 2006). A general population study of more than 3000 people revealed that ex-smokers reported less depression than current smokers (Haukkala et al, 2000). Studies also suggest that smoking increases risk of depression in adolescents. In a prospective study of 2000 young people (8-14 years old) without a history of depression, initiation of smoking was not associated with current depressed mood, although smoking modestly increased the risk of developing depressed mood, suggesting that smoking led to depression (Wu \& Anthony, 1999). This finding was borne out in a larger prospective study of adolescents in which smoking was shown to predispose to the development of depression (Goodman \& Capitman, 2000). Another US study of over 13000 individuals, which used data from the National Household Survey on Drug Abuse, revealed that smoking had a dose relationship with depression in adolescents: the greatest number of depressive symptoms were reported in current smokers and the lowest number in those who had never smoked; in former smokers, depressive symptoms correlated inversely with time since quitting (Martini et al, 2002).

There is evidence of shared genetic factors predisposing individuals to both smoking and depression: higher rates of smoking and major depression have been found in co-twins of monozygotic probands than in co-twins of dizygotic probands (Kendler et al, 1993). It has also been suggested that cigarette smoking and depression are linked by common parameters of deprivation, rather than cigarette smoking causing depression or the converse (Roy et al, 2001). Furthermore, previous studies of associations between depression and smoking might have overestimated the association by ignoring comorbid anxiety and other cofounders. In a large population-based health survey, the association with smoking was strongest for comorbid anxiety and depression, less strong for anxiety alone and only marginal for depression alone (Mykletun et al, 2008). Potential confounders suggested as contributors to the association were somatic symptoms, socio-demographics, alcohol problems and low physical activity. Anxiety and depression were most common in current smokers, followed by ex-smokers and then never-smokers, although no decline in anxiety or depression was found with time since cessation.

\section{Smoking and anxiety}

A US study of 688 youths reported that cigarette smoking increases the risk of certain anxiety disorders during late adolescence and early adulthood (Johnson et al, 2000). Daily smoking has also been associated with an increased risk of the first occurrence of panic attack, with evidence of reduced risk of a panic disorder after smoking cessation in two epidemiological studies of more than 5000 people (Breslau \& Klein, 1999). Perceived stress levels were found to reduce on stopping smoking and increase again on return to smoking (Cohen \& Lichtenstein, 1990). In another study, anxiety 
decreased following the first week of abstinence (West \& Hajek, 1997), which suggests that smoking is chronically anxiogenic rather than anxiolytic. This is consistent with the finding that anxiety is increased among smokers in general population studies (Coultard et al, 2000).

Aside from smoking's apparent anxiogenic action, depressive and anxiety symptoms may increase the risk that an individual will take up smoking because of increased susceptibility to peer influences (results from a prospective study of more than 2000 students; Patton et al, 1998). Similarly, social anxiety disorder seems to predict uptake of smoking (more than 3000 adolescents; Sonntag et al, 2000).

A systematic review revealed high levels of smoking (respectively $40-86 \%$ and $34-61 \%$ ) in both clinical and non-clinical populations with posttraumatic stress disorder (Fu et al, 2007).

\section{Summary}

There appears to be a clear relationship between smoking and depressive and anxiety symptoms, and symptoms reduce after smoking cessation. Smokers are also more likely to think about suicide and have higher suicide rates.

\section{Smoking and schizophrenia}

Precipitator or protector?

There are contradictory research findings regarding a possible link between smoking at an early stage and later development of schizophrenia. Some studies suggest that smoking is a risk factor for schizophrenia. For example, a study of 168 people with schizophrenia found that $90 \%$ had started smoking before the onset of the illness (Kelly \& McCreadie, 1999). The authors postulated that smoking is a marker of the illness and a possible risk factor for schizophrenia. They suggested that repeated activation by nicotine of the mesolimbic system over a prolonged period precipitates the onset of schizophrenia in vulnerable individuals.

Conversely, other studies report that early smoking is associated with a lower rate of subsequent schizophrenia; for example, a large cohort study that adjusted for confounders reported a linear relationship between the number of cigarettes smoked at ages 18-20 and lower risk of schizophrenia (Zammit et al, 2003). These authors proposed that cigarette smoking is an independent protective factor against developing schizophrenia and suggested that this is consistent with animal models that show both neuroprotective effects of nicotine and differential release of prefrontal dopamine in response to nicotine.
People with schizophrenia find it more difficult to ignore distracting stimuli and have been found to have abnormal auditory filtering (Adler et al, 1993). This is referred to as auditory sensory-gating deficit and shows as diminished suppression of auditory-evoked P50 response. This deficit may be related to nicotine receptors since nicotine and cigarette smoking transiently reverse these deficits. Genetic evidence links diminished P50 response with decreased $\alpha_{7}$ subunits of nicotinic receptors in the brains of families affected by schizophrenia and bipolar disorder (Leonard et al, 2001). Since such sensory-gating deficits in schizophrenia can be normalised by nicotine, this was suggested as a possible cause for the high prevalence of smoking in this population.

Severe forms of schizophrenia with poor outcome may be associated with heavy smoking (Aguilar et al, 2005) and it may be that these individuals are vulnerable to both high nicotine dependence and schizophrenia with poor outcome. However, smoking at an early age is also associated with substance misuse, which is a known precipitant for the onset of schizophrenia in those with a genetic predisposition (Williams \& Ziedonis, 2004).

\section{Smoking as self-medication in schizophrenia}

It has been suggested that people with schizophrenia smoke as a form of self-medication.

Effects of smoking on symptoms There is contradictory evidence regarding the association between smoking and the positive and negative symptoms of schizophrenia. Some studies support such as link: for example, smokers with schizophrenia have more positive symptoms and significantly fewer negative symptoms than non-smokers (Goff et al, 1992, Ziedonis et al, 1994); people with schizophrenia report that they smoke primarily for sedative effects and to control negative symptoms (Forchuk et al, 2002).

Others, however, do not suggest such an association. One found limited evidence of a reduction in negative symptoms (Dalack \& MeadorWoodruff, 1996); in another, only $17 \%$ of participants reported that smoking improved their psychotic symptoms (Kelly \& McCreadie, 2000); in a third, smoking was not associated with improvement in positive, negative, cognitive or mood symptoms in 146 people with schizophrenia (Barnes et al, 2006).

As noted above, $\alpha_{7}$ nicotinic receptors are reduced in schizophrenia but are activated by nicotine. However, this activation only lasts for about $10 \mathrm{~min}$ following smoking because of subsequent inactivation or desensitisation of the $\alpha_{7}$ receptors (Kumari \& Postma, 2005). This would support the self-medication hypothesis. 
Smoking decreases blood serum levels of antipsychotics Smoking increases the metabolism of various antipsychotic medications (Campion et al, 2008 , this issue), which may consequently reduce their adverse side-effects (Haustein et al, 2002). There is evidence that smokers on typical antipsychotics smoke less when switched to an atypical with fewer side-effects (McEvoy et al, 1999).

Noting research showing that people with schizophrenia who smoke are prescribed higher doses of antipsychotics than non-smokers, Aguilar et al (2005) suggested that psychiatrists are inadvertently correcting for the effect of smoking on antipsychotic metabolism.

\section{Summary}

A systematic review found no randomised clinical trials that support the self-medication hypothesis (Punnoose \& Belgamwar, 2006). Hypotheses about specific neurochemical interactions between nicotine and smoking are undermined by the general association observed between most types of disorders and smoking (West \& Jarvis 2005) and by high rates of substance misuse in people with schizophrenia.

There seems to be a complex interaction between nicotine dependence and schizophrenic symptoms (Aguilar et al, 2005).

\section{Smoking and other substance misuse}

Smokers are more likely to have problems with drugs and alcohol, and the link with alcohol misuse and dependence is particularly strong (Miller \& Gold, 1998). Alcohol use disorders have been significantly associated with regular heavy smoking (Dierker $e t$ $a l, 2002)$. Smoking at an early age is also associated with substance misuse (Williams \& Ziedonis, 2004) and current daily cigarette smokers are more likely to have a comorbid substance use disorder than people who have never smoked (John et al, 2004). Use of cannabis has also been found to reduce rates of smoking cessation (Ford et al, 2002).

It has been estimated that about half of people with schizophrenia misuse illicit substances and alcohol at some time during their illness (Reiger $e t$ $a l, 1984)$ and those that do have poorer symptomatic and functional outcomes than those that do not (Kavanagh et al, 2002). In a 15-month follow-up study examining the course of substance misuse and daily tobacco use in 103 individuals treated for firstepisode psychosis (Wade et al, 2006), a significant reduction occurred in the rate of any substance misuse but not of daily tobacco use.

\section{Effects of smoking cessation on psychiatric conditions}

\section{Depression and anxiety}

Nicotine withdrawal symptoms related to decreased dopaminergic activity cause significant distress and impairment in at least half of smokers when they quit (Hughes, 2007a). Anger, anxiety, depression, difficulty concentrating, impatience and insomnia peak in the first week and last up to 4 weeks (Hughes, 2007b). Appetite can be increased for more than 10 weeks (Benowitz, 1998) and weight gain following cessation is significant (O'Hara et al, 1998).

Although smokers report that smoking makes them feel calm, this may simply reflect relief of withdrawal from nicotine. The frequent experience of unpleasant withdrawal symptoms in between cigarettes has been suggested as a possible explanation for the association between nicotine dependence and higher rates of mental health problems (Parrott, 2006). Withdrawal symptoms significantly overlap with symptoms of mental illness and it is sometimes difficult to distinguish the two when assessing the impact of smoking cessation. Staff and patients may interpret signs of nicotine withdrawal as a worsening of mental health symptoms that requires relief with cigarettes (Lawn \& Pols, 2003). However, a review showed that smoke-free policies in psychiatric clinics had no negative effect on mental illness even when it led to withdrawal symptoms (Haustein et al, 2002).

A number of studies have shown that quitting smoking exacerbates mental health problems in people with depression. The most recent review (Hughes, 2007c) identified seven empirical trials which excluded smokers with major depression or who were taking antidepressants at the start of the trial but all had methodological limitations. Incidence of current major depressive disorder was $0-14 \%$ among all smokers who tried to quit, $3-24 \%$ in those with previous major depressive disorder who tried to quit and $1-31 \%$ among smokers who became abstinent for several weeks or more. Hughes concluded that smokers with a past history of major depressive disorder are more likely to have a postcessation relapse of depression. However, the evidence is unclear whether abstinence increases the incidence of the disorder or whether treatment with antidepressants prevents post-cessation relapse.

\section{Summary}

There is some evidence that a minority of people with depression who quit smoking experience an increase in depressive symptoms. This group would 
therefore benefit from closer monitoring, especially in the first few weeks following quitting.

\section{Schizophrenia}

There is little evidence to suggest worsening of symptoms after people with schizophrenia stop smoking. For example, a 3-day study of 60 patients on acute psychiatric wards, 44 of whom were smokers, found no clear evidence that stopping smoking exacerbated psychotic illness (Smith et $a l, 1999)$. In another study, of 256 in-patients with chronic schizophrenia (Kitabayashi et al, 2006), a smoke-free policy had only minor unfavourable effects on psychiatric status and body mass index. There was no indication of associated deterioration in symptoms or functioning during a smoking cessation trial involving 298 smokers with psychosis who received NRT, motivational interviewing and CBT (Baker et al, 2006). However, akathisia can occur after smoking cessation (Barnes et al, 2006).

In summary, given that some biochemical and physiological evidence supports the benefits of nicotine to people with schizophrenia, provision of alternative, less-harmful methods of nicotine intake such as NRT is important for very heavy smokers. There is also opportunity for lower doses of antipsychotic medication after cessation and therefore fewer long-term side-effects.

\section{Other effects of smoking cessation}

\section{Aggression}

Reviews of smoke-free policy in mental health and addiction settings (el-Guebaly et al, 2002; Lawn \& Pols, 2005) indicate that total or partial smoking bans had no major untoward effects on behaviour or the frequency of aggression. On one in-patient unit a smoke-free policy had significantly fewer adverse effects than staff anticipated (Patten et al, 1995). In a study in a maximum-security setting, total disruptive behaviour and verbal aggression significantly reduced following a ban (Hempel et al, 2002). Another study, also in a maximum-security setting, noted that a temporary increase in physical aggression towards staff may have occurred with the introduction of a smoking ban, although overall the policy was associated with clear benefits and almost no detectable ill effect (Harris et al, 2007).

\section{Weight}

The increase in weight that smokers experience deters many from attempting to stop and has a potentially significant health impact for those with mental illness. In a large cohort study of the general population (O'Hara et al, 1998), weight gain was often progressive for a period of at least a year; average weight gain in the first year of smoking cessation was about $5 \mathrm{~kg}$ and $33 \%$ of ex-smokers gained more than $10 \mathrm{~kg}$ compared with $6 \%$ of continuing smokers. This weight gain was more than just a return to the weight that smokers would have achieved had they never smoked, and it indicates the potential value of proactively combining healthy eating messages and exercise with smoking cessation.

\section{Smoking and psychiatric medication}

\section{Effect of medication on smoking behaviour}

The choice of antipsychotic medication influences smoking behaviour. Haloperidol has been associated with an increase in smoking (Dawe et al, 1995) and clozapine with a decrease (George et al, 1995). However, in comparison with typical antipsychotics, atypical antipsychotics are associated with reduced smoking (McEvoy et al, 1999; Hempel et al, 2002; Barnes et al, 2006), reduced desire to smoke (Hempel et $a l, 2002)$ and with higher rates of smoking cessation (George et al, 2000). Switching people with schizophrenia from typicals to atypicals may help them to give up smoking (Barnes et al, 2006). This might be explained by the greater capacity of typical antipsychotics to block dopamine $\mathrm{D}_{2}$ receptors. Another possible explanation is the higher level of anticholinergic side-effects of the typicals, which are reduced by smoking (Minzenberg et al, 2004).

\section{Effect of smoking on psychiatric medication}

As noted above, smokers are generally prescribed higher doses of antipsychotic medication than non-smokers. This is because the toxic products of tobacco combustion increase the metabolism of antipsychotics by inducing the cytochrome P450 (CYP) enzyme system (Ziedonis et al, 1994). The enzyme CYP1A2 is responsible for the metabolism of many medications as well as activation of some carcinogens. Smoking can thereby lower the serum levels of medication by as much as $50 \%$ (Wilhelm et al, 2004). Medication metabolised by CYP1A2 includes diazepam, haloperidol (partial), olanzapine (partial), clozapine, mirtazapine (partial) and tricyclics (Bazire, 2003) as well as opiates, barbiturates and benzodiazepines (Schall et al, 1996). 


\section{Difficulties introducing smoke- free policies in mental health settings}

There are many potential barriers to the introduction of smoke-free policies in mental health settings. The poor physical health of people with mental illnesses often does not receive the attention it requires (Phelan et al, 2001) and despite a high general practitioner consultation rate, those with severe mental illness have been less likely than the general population to be offered health promotion interventions such as smoking cessation.

There is a long-standing culture of smoking in mental health settings that may reflect previous token economy models of treatment and also explain higher rates of smoking among psychiatric nursing staff (Department of Health, 2005). In one study (Stubbs et al, 2004), 60\% of staff working in a large psychiatric hospital believed that they should be allowed to smoke with their patients, over half thought that staff smoking with patients is valuable in creating therapeutic relationships and over a fifth that cigarettes should be given to patients to achieve therapeutic goals. In another survey of 2574 National Health Service staff, nearly one in three psychiatric staff was against a smoking ban in their setting and was also less positive about the role of staff in providing smoking cessation intervention (McNally et al, 2006).

Difficulties surrounding the introduction of a smoke-free policy to mental health units can be particularly evident when dealing with acutely disturbed patients. Some staff may see a conflict between doing greatest good for the majority through a smoke-free policy, and an attempt to respond to individual need when dealing with distressed, non-comprehending individuals in crisis (Campion et al, 2008a). Such conflicts can be divisive and have a strong emotional impact on staff, which can contribute to the inconsistent application of a smoke-free policy. Staff have expressed concerns about increased levels of aggression or deterioration of mental health symptoms if smoke-free policies are introduced (Stubbs et al, 2004). These concerns are greater in settings where there is no outside space to smoke and nicotine withdrawal is therefore legally enforced.

The introduction of a smoke-free policy can be difficult without first ensuring that employees are no longer smoking in the workplace. Staff may experience more difficulty with total bans since they continue to smoke during their breaks (Hempel et $a l, 2002)$. The offer of smoking cessation treatment to both staff and patients is felt to be a critical part of a successful implementation of smoke-free policy (McNeill \& Owen, 2005).

\section{Successful policy introduction}

Many of these potential barriers are not borne out by the evidence. In a systematic review of 26 international studies from Australia, Canada and the USA, the frequency of aggression, the use of seclusion, discharge against medical advice and the use of as-needed medication did not increase following a ban (Lawn \& Pols, 2005). Simple smoke-free policies applied in a consistent way to all patients were more effective than selective or gradually introduced bans. Complaints and verbal aggression were associated with selective bans and partial smoking bans have also been shown to be ineffective (Leavell et al, 2006). Although the majority of staff did not favour a total ban on smoking by staff, patients or visitors in some studies, the attitudes of both staff and patients changed to favour a smoke-free environment following introduction of a smoke-free policy (el-Guebaly et al, 2002; Hempel et al, 2002; Lawn \& Pols, 2005).

Smoke-free policy has been successfully implemented in maximum-security psychiatric settings and apprehensions of staff and patients dissipated with time (Hempel et al, 2002). Total disruptive behaviour and verbal aggression significantly reduced following the introduction of the policy. In another study in a maximum-security setting, a tobacco ban was found to be associated with clear benefits and almost no detectable ill-effect, although it may have been associated with a temporary increase in physical aggression towards staff members (Harris et al, 2007).

A recent consultation with key stakeholders in Scotland and review of case studies concluded that most smoke-free policies are introduced in a phased way over time, probably reflecting the preference of those involved in implementation (Bauld et al, 2007), despite the limited evidence from the literature suggesting that phased introduction enables resistance to build up and strategies to develop that enable continued smoking. They concluded that the way a policy is introduced may depend on the environment of the institution but that careful planning and communication are critically important. This concurred with findings following an unsuccessful implementation of a smoke-free policy in Australia, from which it was concluded that the principles of introducing a smoke-free policy must be adapted to meet the needs of each local environment and its specific circumstances (Campion et al, 2008b).

\section{Guidance on introducing smoke- free policies}

The Health Development Agency published guidance (McNeill \& Owen, 2005) to support 
mental health trusts introducing and implementing effective smoke-free policies. This advises on the provision of smoke-free buildings to protect staff, patients and others from the health risks of secondhand smoke and discusses the specific issues facing psychiatric institutions when implementing smokefree policies.

\section{Benefits of smoke-free mental health services}

Smoke-free mental health services will have significant benefits for people with mental illnesses.

\section{Reduction of inequality}

It is estimated that half of the difference in survival to 70 years of age between social classes I and $V$ in the UK is due to the higher prevalence of smoking in class V (Wanless, 2004). People with mental illness already experience health inequality, and smoking exacerbates it. Mental health services committed to a smoke-free policy could help to redress the balance.

\section{Health promotion and addressing unmet needs}

Smoke-free mental health services can help to address physical health issues and health promotion for people with mental health problems. Such work can coordinate with primary care in addressing other physical public health issues such as obesity.

\section{Improved well-being}

Psychological problems decline significantly in smokers who stop smoking for 6 months (Mino et al, 2000). Levels of anxiety reduce following cessation, and quitting smoking is followed by enduring mood improvements (Parrott, 2006). Patients may also experience increased self-esteem following cessation (Cooke, 1991).

\section{Long-term cessation}

A review of smoking bans in the workplace (Fichtenberg \& Glantz, 2002) found 15\% of smokers stopped completely and others reduced their consumption. Bans in mental health settings have had little effect on smoking cessation in the longer term, although this may be partly explained by poor coordination between in-patient, out-patient and smoking cessation services (el-Guebaly et al, 2002; Lawn \& Pols, 2005). Specialist services for smokers with mental illness have achieved abstinence rates as high as those for the general population (Foulds et al, 2006). With improved availability and coordination of smoking cessation treatment, longer-term cessation is likely to increase.

\section{The need for model smoke-free services}

There is need for greater awareness of the harm that smoking causes, especially to people with mental illness, who tend to smoke more. Mental health settings should serve as a model environment in which help is provided for nicotine withdrawal, support is given to smokers wanting to stop, medication is monitored after smoking cessation and weight gain is minimised by encouraging healthy diet and activity. Coupling smoking prohibition with administration of nicotine preparations can be useful in helping smokers to cut down or quit (Haustein et $a l, 2002)$. The introduction of complete smoke-free policies in mental health settings will provide such an environment, in which the dangers of active and passive smoking are appropriately highlighted and people with mental health problems given the same access to smoke-free air as the general population.

There is a danger that services will underestimate the capacity of people with mental health problems to stop smoking because of the stigmatising presumption that psychiatric patients are unable to quit (Smith, 2006). This may then exclude them from mainstream 'stop-smoking' programmes.

\section{Conclusions}

Smoking is the largest single cause of preventable illness in the UK. People with mental health problems smoke significantly more and are therefore at greater risk of smoking-related morbidity and mortality. Smoking affects psychiatric treatment by negatively influencing well-being and psychiatric symptoms, increasing the doses of required medication and causing physical ill health. The effect of environmental tobacco smoke on health is accepted and the Health Act 2006 provides the opportunity to protect both patients and staff from it. This is particularly important in mental health settings, given the vulnerability of psychiatric patients and their greater health inequality.

Introducing smoke-free policies in mental health services will significantly improve health and wellbeing in populations with disproportionate levels of inequality and will therefore play a key part in addressing the physical health needs of people with mental health problems. By considering smoking as a chronic illness, more active intervention in health settings will result. 


\section{Declaration of interest}

None.

\section{References and related articles}

Adler, L. E., Hoffer, L. D., Wiser, A., et al (1993) Normalization of auditory physiology by cigarette smoking in schizophrenic patients. American Journal of Psychiatry, 150, 1856-1861.

Aguilar, M. C., Gurpegui, M., Diaz, F. J., et al (2005) Nicotine dependence and symptoms in schizophrenia. Naturalistic study of complex interactions. British Journal of Psychiatry, 186, 215-221.

American Psychiatric Association (1995) Diagnostic and Statistical Manual of Mental Disorders (3rd edn) (DSM-III). APA

Baker, A., Richmond, R., Haile, M., et al (2006) A randomized controlled trial of a smoking cessation intervention among people with a psychotic disorder. American Journal of Psychiatry, 163, 1934-1942.

Barnes, M., Lawford, B. R., Burton, S. C., et al (2006) Smoking and schizophrenia: is symptom profile related to smoking and which antipsychotic medication is of benefit in reducing cigarette use? Australian and New Zealand Journal of Psychiatry, 40, 575-580.

Bauld, L., Ferguson, J., Kerr, A., et al (2007) Moving towards smoke-free mental health services. Mental Health Review Journal, 12, 18-24.

Bazire, S. (2003) Psychotropic Drug Directory 2003/2004. Fivepin

Benowitz, N. L. (1998) Nicotine Safety and Toxicity. Oxford University Press.

Breslau, N. \& Klein, D. F. (1999) Smoking and panic attacks: an epidemiological investigation. Archives of General Psychiatry, 56, 1141-1197.

Breslau, N., Novak, S. P. \& Kessler, R. C. (2004) Psychiatric disorders and stages of smoking. Biological Psychiatry, 55, 69-76.

Brown, S., Barraclough, B. \& Inskip, H. (2000) Causes of the excess mortality of schizophrenia. British Journal of Psychiatry, 177, 212-217.

Campion, J., McNeill, A. \& Checinski, K. M. (2006) Exempting mental health units from smoke-free laws. BMJ, 333, 407-408.

Campion, J., Checinski, K. \& Nurse, J. (2008a) Review of smoking cessation treatments for people with mental illness. Advances in Psychiatric Treatment, 14, 208-216.

Campion, J., Lawn, S., Brownlie, A., et al (2008b) Implementing smoke-free policies in mental health units: learning from unsuccessful experience. Australasian Psychiatry, 16, 92-97.

Chambers, R. A., Krystal,J.H. \&Self, D. W. (2001) Aneurobiological basis for substance abuse comorbidity in schizophrenia. Biological Psychiatry, 50, 71-83.

Cohen, S. \& Lichtenstein, E. (1990) Perceived stress, quitting smoking and smoking relapse. Health Psychology, 9, 466-478.

Cooke, A. (1991) Maintaining a smoke-free psychiatric ward. Dimensions in Health Service, 68, 14-15.

Coultard, M., Farrell, M., Singleton, N., et al (2000) Tobacco, Alcohol and Drug Use and Mental Health. UK Department of Health.

Cuijpers, P., Smit, F., ten Have, M., et al (2007) Smoking is associated with first-ever incidence of mental disorders: a prospective population-based study. Addiction, 102, 1303-1309.

Dalack, G. W. \& Meador-Woodruff, J. H. (1996) Smoking, smoking withdrawal and schizophrenia: case reports and a review of the literature. American Journal Psychiatry, 155, 1490-1501.

Dawe, S., Gerada, C., Russell, M. A. H., et al (1995) Nicotine intake in smokers increases following a single dose of haloperidol. Psychopharmacology, 117, 110-115.

Department of Health (2005) Consultation on The Smokefree Elements of the Health Improvement and Protection Bill. Department of Health.

Department of Health (2006) Smoke-free Premises and Vehicles. Consultation on Proposed Regulations to be Made under the Powers in the Health Bill. TSO (The Stationery Office).

Dierker, L. C., Avenevoli, S., Stolar, M., et al (2002) Smoking and depression: an examination of mechanisms of comorbidity. American Journal Psychiatry, 159, 947-531.
Doll, R., Peto, R., Boreham, J., et al (2004) Mortality in relation to smoking: 50 years' observation on male British doctors. $B M J, 328,745$

el-Guebaly, N., Cathcart, J., Currie, S., et al (2002) Public health and therapeutic aspects of smoking bans in mental health and addiction settings. Psychiatric Services, 53, 1617-1622.

Farrell, M., Howes, S., Bebbington, P., et al (2001) Nicotine, alcohol and drug dependence and psychiatric morbidity. Results of a national household survey. British Journal Psychiatry, 179, 432-437.

Federal Trade Commission (2007) Cigarette Report for 2004 and 2005. US Federal Trade Commission.

Fichtenberg, C. M. \& Glantz, S. A. (2002) Effect of smoke-free workplaces on smoking behaviour: systematic review. BMJ 325, 188.

Forchuk, C., Norman, R., Malla, A., et al (2002) Schizophrenia and the motivation for smoking. Perspectives on Psychiatric Care, 38(2), 41-49.

Ford, D., Vua, H. \& Anthony, J. (2002) Marijuana use and cessation of tobacco smoking in adults from a community sample. Drug and Alcohol Dependence, 67, 243-248.

Foulds, J. G. K., Steinberg, M. B., Richardson, D., et al (2006) Factors associated with quitting smoking at a tobacco dependence treatment clinic. American Journal of Health Behavior, 30, 400-412.

Fu, S., McFall, M., Saxon, A., et al (2007) Post-traumatic stress disorder and smoking: a systematic review. Nicotine and Tobacco Research, 9, 1071-1084.

George, T. P., Sernyak, M. J., Ziedonis, D. M., et al (1995) Effects of clozapine on smoking in chronic schizophrenic outpatients. Journal of Clinical Psychiatry, 56, 344-346.

George, T. P., Ziedonis, D. M., Feingold, A., et al (2000) Nicotine transdermal patch and atypical antipsychotic medications for smoking cessation in schizophrenia. American Journal Psychiatry, 157, 1835-1842.

Goddard, E. (2008) Smoking and Drinking among Adults, 2006. General Household Survey 2006. Office for National Statistics.

Goff, D. C., Henderson, D. C. \& Amico, E. (1992) Cigarette smoking in schizophrenia: relationship to psychopathology and medication side effects. American Journal Psychiatry, 149, 1191-1194

Goodman, E. \& Capitman, J. (2000) Depressive symptoms and cigarette smoking among teens. Paediatrics, 106, 748-755.

Gotti, C., Fornasari, D. \& Clementi, F. (1997) Human neuronal nicotinic receptors. Progress in Neurobiology, 53, 199-237.

Harris, G. T., Parle, D. \& Gagne, J. (2007) Effects of a tobacco ban on long-term psychiatric patients. Journal of Behavioral Health Services and Research, 34, 43-55.

Haukkala, A., Uutela, A., Vartiainen, E., et al (2000) Depression and smoking cessation: the role of motivation and self efficacy. Addictive Behaviour, 25, 311-316.

Haustein, K. O., Haffner, S. \& Woodcock, B. G. (2002) A review of the pharmacological and psychopharmacological aspects of smoking and smoking cessation in psychiatric patients. International Journal of Clinical Pharmacology and Therapeutics, 40, 404-418.

Hempel, A. G., Kownacki, R., Malin, D. H., et al (2002) Effect of a total smoking ban in a maximum security psychiatric hospital. Behavioral Science and the Law, 20, 507-522.

Hennekens, C. H., Hennekens, A. R., Hollar, D., et al (2005) Schizophrenia and increased risks of cardiovascular disease. American Heart Journal, 150, 1115-1121.

Hughes, J. R. (1999) Co-morbidity and smoking. Nicotine and Tobacco Research, 1, S149-S152.

Hughes, J. R. (2007a) Effects of abstinence from tobacco: etiology, animal models, epidemiology, and significance: a subjective review. Nicotine and Tobacco Research, 9, 329-339.

Hughes, J. R. (2007b) Effects of abstinence from tobacco: valid symptoms and time course. Nicotine and Tobacco Research, 9, 315-327.

Hughes, J. R. (2007c) Depression during tobacco abstinence. Nicotine and Tobacco Research, 9, 443-446.

Jamrozik, K. (2005) Estimate of deaths attributable to passive smoking among adults: database analysis. BMJ, 330, 812.

Jochelson, J. \& Mairowski, B. (2006) Clearing the Air. Debating Smoke-Free Policies in Psychiatric Units. King's Fund. 
John, U., Meyer, C., Rumpf, H. J., et al (2004) Smoking, nicotine dependence and psychiatric comorbidity - a population-based study including smoking cessation after three years. Drug and Alcohol Dependence, 76, 287-295.

Johnson, J. G., Cohen, P., Pine, D. S., et al (2000) Association between cigarette smoking and anxiety disorders during adolescence and early adulthood. JAMA, 284, 2348-2351.

Joukamaa, M., Heliövaara, M., Knekt, P., et al (2001) Mental disorders and cause-specific mortality. British Journal Psychiatry, 179, 498-502.

Kavanagh, D. J., McGrath, J., Saunders, J. B., et al (2002) Substance misuse in patients with schizophrenia: epidemiology and management. Drugs, 62, 743-755.

Kelly, C. \& McCreadie, R. G. (1999) Smoking habits, current symptoms, and premorbid characteristics of schizophrenic patients in Nithsdale, Scotland. American Journal Psychiatry, 156, 1751-1757.

Kelly, C. \& McCreadie, R. (2000) Cigarette smoking and schizophrenia. Advances in Psychiatric Treatment, 6, 327-331.

Kendler, K. S., Neale, M. C., Maclean, C. J., et al (1993) Smoking and major depression: a causal analysis. Archives of Genera Psychiatry, 50, 36-43.

Khalil, A. A., Steyn, S. \& Castagnoli, N. (2000) Isolation and characterization of a monoamine oxidase inhibitor from tobacco leaves. Chemical Research in Toxicology, 13, 31-35.

Kitabayashi, Y., Narumoto, J., Shibata, K., et al (2006) Effect of institutional smoking prohibition on Japanese inpatients with chronic schizophrenia. Nihon Arukoru Yakubutsu Igakkai Zasshi, 41, 128-133.

Klimek, V., Zhu, M.-Y. \& Dilley, G. (2001) Effects of long-term cigarette smoking on the locus coerulus. Archives of General Psychiatry, 58, 821-827.

Klungsoyr, O., Nygard, J. F., Sorensen, T., et al (2006) Cigarette smoking and incidence of first depressive episode: an 11-year, population-based follow-up study. American Journal of Epidemiology, 163, 421-432.

Kumari, V. \& Postma, P. (2005) Nicotine use in schizophrenia: the self medication hypothesis. Neuroscience and Biobehavioural Reviews, 29, 1021-1034.

Lawn, S. \& Pols, R. (2003) Nicotine withdrawal: pathway to aggression and assault in the locked psychiatric ward? Australasian Psychiatry, 1, 199-203.

Lawn, S. \& Pols, R. (2005) Smoking bans in psychiatric settings? A review of the research. Australian and New Zealand Journal of Psychiatry, 39, 866-855.

Lawn, S. J., Pols, R. G. \& Barber, J. G. (2002) Smoking and quitting: a qualitative study with community-living psychiatric clients. Social Science and Medicine, 54, 93-104.

Leavell, N. R., Muggli, M. E., Hurt, R. D., et al (2006) Blowing smoke: British American Tobacco's air filtration scheme. BMJ, 332, 227-229.

Leonard, S., Adler, L. E., Benhammou, K., et al (2001) Smoking and mental illness. Pharmacology, Biochemistry and Behavior, 70, 561-570

Malone, K. M., Waternaux, C., Haas, G. L., et al (2003) Cigarette smoking, suicidal behavior, and serotonin function in major psychiatric disorders. American Journal Psychiatry, 160, 773-779.

Martini, S., Wagner, F. A. \& Anthony, J. C. (2002) The association of tobacco smoking and depression in adolescence: evidence from the United States. Substance Use and Misuse, 37, 1853-1867.

McEvoy, J. P., Freudenreich, O. \& Wilson, W. H. (1999) Smoking and therapeutic response to clozapine in patients with schizophrenia. Biological Psychiatry, 46, 125.

McNally, L., Oyefeso, A., Annan, J., et al (2006) A survey of staff attitudes to smoking-related policy and intervention in psychiatric and general health care. Journal of Public Health, 28, 192-196.

McNeill, A. \& Owen, L. (2005) Guidance for Smokefree Hospital Trusts. Health Development Agency.

Miller, N. \& Gold, M. (1998) Comorbid cigarette and alcohol addiction: epidemiology and treatment. Journal of Addictive Disorders, 17, 55-66.

Mino, Y., Shigemi, J., Otsu, T., et al (2000) Does smoking cessation improve mental health? Psychiatry and Clinical Neurosciences, 54, 169-172.
Minzenberg, M. J., Poole, J. H., Benton, C., et al (2004). Association of anticholinergic load with impairment of complex attention and memory in schizophrenia. American Journal of Psychiatry, 161, 116-124.

Mykletun, A., Overland, S., Aarø, L.E., et al (2008) Smoking in relation to anxiety and depression: Evidence from a large population survey. The HUNT study. European Psychiatry, 23, 77-84.

Nurse, J. \& Campion, J. (2006) Mental health and well-being in the South East. Care Services Improvement Partnership.

O'Hara, P., Connett, J. E., Lee, W. W., et al (1998) Early and late weight gain following smoking cessation in the Lung Health Study. American Journal of Epidemiology, 148, 821-830.

Parrott, A.C. (2006) Nicotine psychobiology: how chronic-dose prospective studies can illuminate some of the theoretical issues from acute-dose research. Psychopharmacology (Berlin), 184, 567-576.

Patten, C. A., Bruce, B. K., Hurt, R. D., et al (1995) Effects of a smokefree policy on an inpatient psychiatric unit. Tobacco Control, 4, 373-379.

Patton, G. C., Carlin, J. B., Coffey, C., et al (1998) Depression, anxiety and smoking initiation: a prospective study over 3 years. American Journal of Public Health, 88, 1518-1522.

Peto, R., Darby, S., Deo, H., et al (2000) Smoking, smoking cessation, and ling cancer in the UK since 1950: combination of national statistics with two case control studies. BMJ, 321, 323-329.

Phelan, M., Stradins, L. \& Morrison, S. (2001) Physical health of people with severe mental illness. BMJ, 322, 443-444.

Prochaska, J., Hall, S. \& Bero, L. (2008) Tobacco use among individuals with schizophrenia: what role has the tobacco industry played? Schizophrenia Bulletin, 28 Mar.

Punnoose, S. \& Belgamwar, M. R. (2006) Nicotine for schizophrenia. Cochrane Database of Systematic Reviews, issue 1 (DOI: 10.1002/14651858). John Wiley \& Sons.

Reiger, D. A, Meyers, J. K., Kramer, M., et al (1984) The NIMH Epidemiologic Catchment Area program. Historical epidemiology of comorbidity, context, major objectives, and study population characteristics. Archives of General Psychiatry, 41, 934-941.

Roy, K., Parker, G., Mitchell, P., et al (2001) Depression and smoking: examining correlates in a subset of depressed patients. Australian and New Zealand Journal of Psychiatry, 35, 329-335.

Royal College of Physicians (2000) Nicotine Addiction in Britain. Royal College of Physicians of London.

Scientific Committee on Tobacco and Health (2004) Secondhand Smoke: Review of Evidence since 1998. Update of Evidence on Health Effects of Secondhand Smoke. Department of Health.

Schall, U. S., Pries, E., Katta, T., et al (1996) Pharmacokinetic and pharmacodynamic interactions in an outpatient maintenance therapy of intravenous heroin users with levomethadone. Addiction Biology, 1, 105-113.

Smith, M. J. (2006) Risks of "passivity smoking". BMJ,11 September (http://bmj.com/cgi/eletters/333/7565/407\#141586).

Smith, C. M., Pristach, C. A. \& Cartagena, M. (1999) Obligatory cessation of smoking by psychiatric inpatients. Psychiatric Services, 50, 91-94.

Sonntag, H., Wittchen, H. U., Hofler, M., et al (2000) Are social fears and DSM-IV social anxiety disorder associated with smoking and nicotine dependence in adolescents and young adults? European Psychiatry, 15, 67-74.

Spring, S., Pingitore, R. \& McChargue, D. E. (2003) Reward value of cigarette smoking for comparably heavy smoking schizophrenic, depressed and nonpatient smokers. American Journal of Psychiatry, 160, 316-322.

Stubbs, J., Haw, C. \& Garner, L. (2004) Survey of staff attitudes to smoking in a large psychiatric hospital. Psychiatric Bulletin, 28, 204-207.

Sullivan, M. A. \& Covey, L. S. (2002) Nicotine dependence: the role for antidepressants and anxiolytics. Current Opinion in Investigational Drugs, 3, 262-271.

Taylor, T., Lader, D., Bryant, A., et al (2006) Smoking-related Behaviour and Attitudes, 2005. Office for National Statistics (http://www.statistics.gov.uk/downloads/theme_health/ Smoking2005.pdf). 
Wade, D., Harrigan, S., Edwards, J., et al (2006) Course of substance misuse and daily tobacco use in first-episode psychosis. Schizophrenia Research, 81, 145-150.

Wanless, D. (2004) Securing Good Health for the Whole Population. TSO (The Stationery Office).

Watkins, S. S., Koob, G. F. \& Markou, A. (2000) Neural mechanisms underlying nicotine addiction: acute positive reinforcement and withdrawal. Nicotine and Tobacco Research, 2, 19-37.

West, R. \& Hajek, P. (1997) What happens to anxiety levels on giving up smoking? American Journal Psychiatry, 154, 1589-1592.

West, R. \& Jarvis, M. (2005) Tobacco smoking and mental disorder. Italian Journal of Psychiatry and Behavioural Science, 15, 10-17.

Whincup, P. H., Gilg, J. A., Emberson, J. R., et al (2004) Passive smoking and risk of coronary heart disease and stroke: a prospective study with cotinine measurement. BMJ, 329, 200-205.

Wilhelm, K., Arnold, K., Niven, H., et al (2004) Grey lungs and blue moods: smoking cessation in the context of lifetime depression history. Australian and New Zealand Journal of Psychiatry, 38, 896-905.

Wilhelm, K., Mitchell, P., Slade, T., et al (2003) Prevalence and correlates of DSM-IV major depression in an Australian national survey. Journal of Affective Disorders, 75, 155-162.

Williams, J. M. \& Ziedonis, D. M. (2004) Addressing tobacco among individuals with a mental illness or an addiction. Addictive Behaviours, 29, 1067-1083.

World Health Organization (1992) The ICD-10 Classification of Mental and Behavioural Disorders: Clinical Descriptions and Diagnostic Guidelines. WHO.

World Health Organization (2006) Tobacco: Deadly in any Form or Disguise (http:/ / www.who.int/tobacco/communications / events/wntd/2006/Tfi_Rapport.pdf).

Wu, L. T. \& Anthony, J. C. (1999) Tobacco smoking and depressed mood in late childhood and early adolescence. American Journal of Public Health, 89, 1837-1840.

Zammit, S., Allebeck, P., Dalman, C., et al (2003) Investigating the association between cigarette smoking and schizophrenia in a cohort study. American Journal Psychiatry, 160, 2216-2221.

Ziedonis, D. M., Kosten, T. R., Glazer, W. M., et al (1994) Nicotine dependence and schizophrenia. Hospital Community Psychiatry, 45, 204-206.

\section{MCQs}

1 Globally each year, smoking kills:

a 1 million

b 2 million

c 3 million

d 5 million

e 10 million.

2 Death occurs 15 years earlier in:

a 1 in 10 smokers

b 1 in 8 smokers

c 1 in 6 smokers

d 1 in 4 smokers

e 1 in 2 smokers.
3 The following is not true about smoking and depression:

a people with depressive or anxiety disorders are twice as likely to smoke as those without

b smokers are more likely to think about suicide and have higher suicide rates

c smoking increases risk of depression

d higher rates of smoking and major depression have been found in dizygotic than in monozygotic twins

e previous studies of associations between depression and smoking might have overestimated the association while ignoring comorbid anxiety and other confounders.

4 The following is not true about smoking and schizophrenia:

a a diagnosis of schizophrenia increases risk of death from respiratory disease to 10 times that for the general population

b smoking increases the metabolism of various antipsychotics and smokers receive higher doses of such medication for treatment of schizophrenia

c smoking cessation causes deterioration of symptoms of schizophrenia

d atypical antipsychotics are associated with reduced smoking compared with typical antipsychotics

e akathisia can occur after smoking cessation

5 Smoking decreases blood serum levels of:

a noradrenaline

b serotonin

c dopamine

d MAO-B

e glutamate. 